Article

\title{
Self-Compacting Concrete Reinforced with Twisted-Bundle Macro-Synthetic Fiber
}

\author{
Estela Oliari Garcez ${ }^{1, * \mathbb{D}}$, Muhammad Ikramul Kabir ${ }^{1}$, Alastair MacLeod ${ }^{2} \mathbb{D}$, \\ Mahbube Subhani ${ }^{1}\left(\mathbb{D}\right.$ and Kazem Ghabraie ${ }^{1}$ (D) \\ 1 School of Engineering, Faculty of Science, Engineering and Built Environment Deakin University, \\ Victoria 3216, Australia; m.kabir@deakin.edu.au (M.I.K.); mahbube.subhani@deakin.edu.au (M.S.); \\ k.ghabraie@deakin.edu.au (K.G.) \\ 2 Institute for Frontier Materials, Deakin University, Victoria 3216, Australia; \\ alastair.macleod@research.deakin.edu.au \\ * Correspondence: estela.o@deakin.edu.au; Tel.: +61-352273125
}

Received: 1 May 2019; Accepted: 18 June 2019; Published: 21 June 2019

Featured Application: Precast concrete industry.

\begin{abstract}
The use of self-compacting concrete (SCC) reinforced with fibers has great potential in the precast concrete industry as the concrete can be delivered straight into the moulds, without any vibration or compacting effort. Similarly, it has the potential to replace traditional steel reinforcement depending on the design requirements. Novel synthetic fibers have recently become available in the market, but still, limited information is available on the performance of SCC reinforced with such fibers. This paper investigates the use of twisted-bundle macro-synthetic fiber in self-compacting concrete. Three different concrete mixtures with fiber dosage of 4,6 , and $8 \mathrm{~kg} / \mathrm{m}^{3}$ were produced in large scale batches, and their performance was compared in terms of slump-flow, compressive strength, split tensile strength, modulus of elasticity, and flexural strength. Moreover, a comprehensive evaluation of the post-cracking residual strength is presented. It was found that the mixture with $4 \mathrm{~kg} / \mathrm{m}^{3}$ fiber content has the most satisfactory flowability, whereas $8 \mathrm{~kg} / \mathrm{m}^{3}$ mixture achieved the highest residual flexural strength. Based on the observed post-cracking behavior, a simplified stress-crack opening constitutive law is proposed. Since the fiber dosage affects the residual flexural strength, a factor related to fiber content is recommended while determining the ultimate residual flexural strength.
\end{abstract}

Keywords: self-compacting concrete; synthetic fibers; stress-crack opening relationship

\section{Introduction}

Fiber-reinforced concrete has gained wide popularity due to the beneficial effect of fibers in improving toughness and ductility, crack resistance, tensile strength, impact and fatigue resistance, and durability [1-5]. The use of macrofibers, such as steel fibers, as reinforcement in concrete is well-established in applications such as industrial pavements, precast structural elements, tunnel lining, etc. [3]. Several guidelines and specifications for steel-fiber reinforced concrete (SFRC) are currently available to support the design of elements and structures with such material [6-9]. However, in applications such as the precasting of thin elements, the use of rigid steel fibers is not the most suitable option, due to the reduced concrete workability, difficulties in placement and finishing, as well as hazards in handling due to the stiffness of the fibers. Therefore, there is a high demand for alternative fibers that can effectively overcome such limitations in fiber-reinforced concrete (FRC) for structural applications. 
Self-compacting concrete (SCC) was first developed in 1988 to achieve more durable concrete structures [10], and since then it has been increasingly adopted by the construction industry. Due to its high flowability, self-compacting concrete is compacted by its self-weight without any vibration or added compacting effort [11]. The self-compacting properties also have an impact on timescales and production efficiency, improving working conditions, and the health of construction workers [12]. The self-compacting properties are beneficial in a wide range of applications, from reinforced-concrete columns in high-rise buildings to structural upgrade and retrofit [13]. Another application of this technology is in the precast concrete industry. Precast elements often require the use of high-strength concrete to provide sufficient early-age strength development to allow for early demolding, as well as lifting and transportation to the construction site.

High-strength concrete is more brittle than normal concrete, and this limitation can also be ameliorated with the addition of fibers to increase its ductility [4,14]. The use of fiber-reinforced high-strength self-compacting concrete seems to be a viable solution for the precast concrete industry, as the concrete can be delivered straight into the molds, without any vibration or compacting effort, increasing production quotas and cost savings, allowing the production of slender elements, and ultimately improving quality and durability of structures.

The performance of SCC with steel fibers [2,15-21] and synthetic fibers [22,23], in hybrid and non-hybrid mixtures, has been extensively reported in the literature. However, in the recent years, new synthetic fibers have become available in the market-for instance, twisted-bundle macro-synthetic fiber-and yet limited information is available on the performance of SCC reinforced with such fibers.

Twisted-bundle macro-synthetic fiber is a blend of two types of fibers: (i) Fibrillated polypropylene fibers to reduce and control shrinkage and temperature cracking, and (ii) very heavy-duty twisted-bundle monofilament fiber made of a robust synthetic copolymer, to increase load-transfer and post-crack performance. A recent study [24] reported the effects of twisted-bundle macro-synthetic fibers on the mechanical properties of high-strength concrete. However, this study did not consider the flexural performance and the post-cracking flexural performance of the twisted-bundle macro-synthetic fiber-reinforced concrete. Another study [25] reported the effect of twisted-bundle macro-synthetic fibers on fresh and mechanical properties of ultra-high performance self-compacting concrete. However, the composites reported in this work did not include coarse aggregate, and again, the post-cracking behavior was not investigated. To the authors' best knowledge, no comprehensive study on the flexural performance and the post-cracking behavior of FRC with twisted-bundle macro-synthetic fibers is available in the literature. Yet the post-cracking residual strength is the most important property of FRC and, therefore, its flexural performance should be deeply investigated.

In order to predict the flexural capacity of FRC, the material behavior and its constitutive law should be examined. The FRC may exhibit strain-hardening or softening behavior. Most of the available literature reports on the strain softening behavior due to the extensive research on SFRC $[9,14,18,26]$. Nevertheless, while associating the strain-softening behavior with crack opening, the steel FRC and synthetic FRC may not reveal the same response. Since the fibers contribute to the post-cracking stage, fracture mechanics-based constitutive law (stress-crack opening relationship) is usually used rather than continuous mechanics-based model (stress-strain relationship). For simplified stress-crack opening relationship, rigid plastic and linear elastic softening models can be found in available literature $[27,28]$. However, the effect of fiber dosage is not considered in these models.

This paper presents the findings of experimental investigations conducted on the effect of twisted-bundle macro-synthetic fibers on the compressive strength, tensile strength, flexural strength, and residual flexural performance of high strength self-compacting fiber-reinforced concrete, as well as the fresh properties of the SCC mixtures. Based on the post-cracking behavior observed in the experiments, a simplified stress-crack opening constitutive law is proposed, considering the effect of fiber dosage while determining the section moment capacity. 


\section{Materials and Methods}

\subsection{Materials}

The twisted-bundle macro-synthetic fiber used in this study is a high-performance fiber, which is made of $100 \%$ virgin copolymer/polypropylene and is a combination of a twisted-bundle non-fibrillating monofilament and a fibrillating network fiber (Figure 1). The fibers are produced by Forta Corporation. Details on the fibers are presented in Table 1, while the fiber dosages used in the batches are given in Table 2. The dosages were chosen based on previous results [25] indicating that dosages beyond $9 \mathrm{~kg} / \mathrm{m}^{3}$ cause a significant decrease in the flowability. The coarse aggregates used in the mixtures were $14 \mathrm{~mm}$ white pebbles and $10 \mathrm{~mm}$ bluestone. Fine sand and ramp-washed sand were used as the fine aggregates. A combination of 50\% eco-blend cement (30\% ground granulated blast furnace slag blended cement) and 50\% general purpose cement were used as binder, with a water-cement ratio of 0.42 . Two high range water reducers were used: One to decrease the viscosity of concretes and extended rheology maintenance, and the other to improve slump retention and workability. The mixture proportions of concrete is not included due to intellectual property restrictions. However, this information is not essential in reaching the general conclusions of this study. The reported mechanical and rheological properties of the mixture should suffice to replicate and validate the results of this study. Since the purpose of this research was to develop fiber-reinforced self-compacting concrete for precasting concrete components, this work does not present results on self-compacting concrete without the addition of fibers.

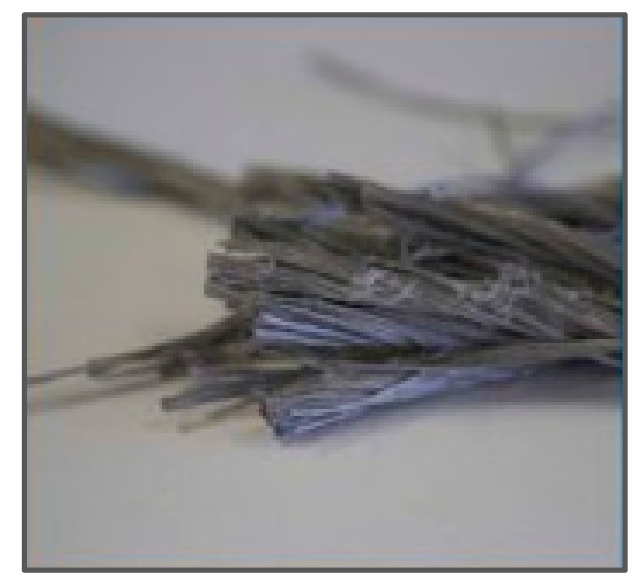

Figure 1. Twisted-bundle macro-synthetic fibers.

Table 1. Fiber properties as per manufacturer's specification.

\begin{tabular}{ccccc}
\hline $\begin{array}{c}\text { Fiber Length } \\
(\mathbf{m m})\end{array}$ & $\begin{array}{c}\text { Tensile } \\
\text { Strength } \\
\mathbf{( M P a )}\end{array}$ & Fiber Form & $\begin{array}{c}\text { Specific } \\
\text { Gravity }\end{array}$ & $\begin{array}{c}\text { Acid/Alkali } \\
\text { Resistance }\end{array}$ \\
\hline 54 & $570-660$ & $\begin{array}{c}\text { Blend of twisted bundle of } \\
\text { monofilament and } \\
\text { fibrillated network }\end{array}$ & 0.91 & Excellent \\
\hline
\end{tabular}

Table 2. Concrete batch identifications.

\begin{tabular}{ccc}
\hline Batch Designation & $\begin{array}{c}\text { Fiber Mass Dosage } \\
\left(\mathbf{k g} / \mathbf{m}^{\mathbf{3}}\right)\end{array}$ & Fiber Volume Dosage (\%) \\
\hline FF4 & $4 \mathrm{~kg} / \mathrm{m}^{3}$ & $0.44 \%$ \\
FF6 & $6 \mathrm{~kg} / \mathrm{m}^{3}$ & $0.66 \%$ \\
FF8 & $8 \mathrm{~kg} / \mathrm{m}^{3}$ & $0.88 \%$ \\
\hline
\end{tabular}




\subsection{Methods}

All mixtures were produced at a ready-mixture concrete plant located in Geelong, Australia. To mimic a real-scale production, $4 \mathrm{~m}^{3}$ of concrete was produced in a conventional concrete agitator truck for each batch. The mixture time between dropping the materials into agitator and casting was approximately $30 \mathrm{~min}$. All samples were demolded $24 \mathrm{~h}$ after casting and cured in a water tank up to the age of 28 days.

\subsubsection{Slump-Flow Test}

The fresh properties were assessed using the slump flow test, as per the Australian Standard AS 1012.3.5 [29]. This test method was used due to its simplicity, quick execution, and broad acceptance within the industry.

\subsubsection{Compressive Strength, Tensile Strength, and Modulus of Elasticity}

A total of 12 cylinders of $100 \mathrm{~mm}$ diameter and $200 \mathrm{~mm}$ height were fabricated from each batch for assessing the 28-day compressive strength, the split tensile strength, and the modulus of elasticity.

\subsubsection{Flexural Strength and Residual Flexural Strength}

Crack mouth opening displacement (CMOD) tests are normally used to study the effect of fibers on the post-cracking behavior of concrete and displays the ability of fibers to redistribute stresses and bridge the cracks formed. The tests were conducted following the BS EN 14651:2005 + A1:2007 [6], which measures the opening of the crack at mid-span using a displacement transducer mounted along the longitudinal axis. This method was previously used to investigate the post-cracking performance of macro-synthetic fibers in concrete [30-32].

A total of four beams were cast per concrete batch. The beam dimensions were $700 \mathrm{~mm} \times 150 \mathrm{~mm}$ $\times 150 \mathrm{~mm}$ (Figure 2), with a span length of $500 \mathrm{~mm}$. A notch (25 mm depth and $5 \mathrm{~mm}$ width) was cut in the middle of the beam to control the crack initiation and propagation along the initially induced notch. The test was conducted under three-point bending loading conditions, with the load applied at a constant CMOD rate of $0.05 \mathrm{~mm} / \mathrm{min}$ up to CMOD $=0.1 \mathrm{~mm}$, followed by a constant CMOD rate of $0.2 \mathrm{~mm} / \mathrm{min}$. The load $(\mathrm{kN})$ and CMOD $(\mathrm{mm})$ were recorded for the analysis of residual flexural strength at various CMODs. CMOD1 to CMOD4 correspond to CMODs of $0.5 \mathrm{~mm}, 1.5 \mathrm{~mm}, 2.5 \mathrm{~mm}$, and $3.5 \mathrm{~mm}$ respectively. The loads corresponding to each CMOD were recorded as $F_{j}$.

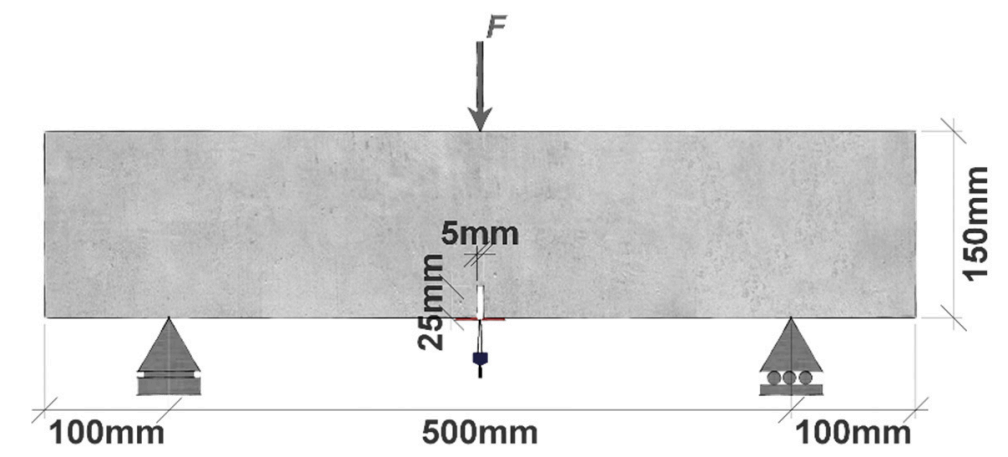

Figure 2. Setup for the notched three-point bending test according to BS EN 14651:2005.

The flexural strength $f_{L}$ (MPa) was calculated according to BS EN 14651:2005+A1:2007 [6], using Equation (1).

$$
f_{L}=\frac{3 F_{L} l}{2 b h_{s p}^{2}}
$$


where, $F_{L}=$ the load corresponding to the limit of proportionality, $l=$ span length, $b=$ width of the specimen, and $h_{s p}=$ distance between the tip of the notch and the top of the specimen. $F_{L}$ was determined by the highest load within the first CMOD interval of $0.05 \mathrm{~mm}$.

The residual flexural strengths $f_{R j}(j=1,2,3,4)$ were calculated using Equation (2), according to BS EN 14651:2005 + A1:2007 [6].

$$
f_{R j}=\frac{3 F_{j} l}{2 b h_{s p}^{2}}
$$

where, $F_{j}=$ load corresponding to the $j$-th recorded CMOD.

\section{Experimental Results and Discussion}

\subsection{Slump-Flow Test}

All mixtures were designed to reach a slump flow diameter of minimum $500 \mathrm{~mm}$, without any bleeding or segregation. Flow test results are presented in Table 3. Figure 3 shows the appearance of FF6 just after the flow test. The mixture with the highest dosage of fibers, FF8, had notable water bleeding and was initially very stiff. The initial $30 \mathrm{~min}$ mixture time was then increased by $10 \mathrm{~min}$ when the mixture became less stiff, but the desirable fresh properties were still not satisfactory. As previously reported in the literature, workability is easily affected by the type of fiber, dosage, length, and shape configuration $[25,33]$. Also, fibers increase the concrete mixture viscosity by absorbing the cement paste; therefore an increase in the volume of fibers may result in poorer concrete workability [24]. The flow test results in this paper demonstrate the deleterious effect of higher fiber dosages in the workability of self-compacting concrete. For the mixture containing $8 \mathrm{~kg} / \mathrm{m}^{3}$ of fiber, further improvements in the mixture proportion would be necessary to achieve the desirable self-compacting properties.

Table 3. Slump-flow test results.

\begin{tabular}{cccc}
\hline Batch Description & FF4 & FF6 & FF8 \\
\hline $\begin{array}{c}\text { Flow test } \\
\text { Diameter }(\mathrm{mm})\end{array}$ & 570 & 650 & 440 \\
\hline
\end{tabular}

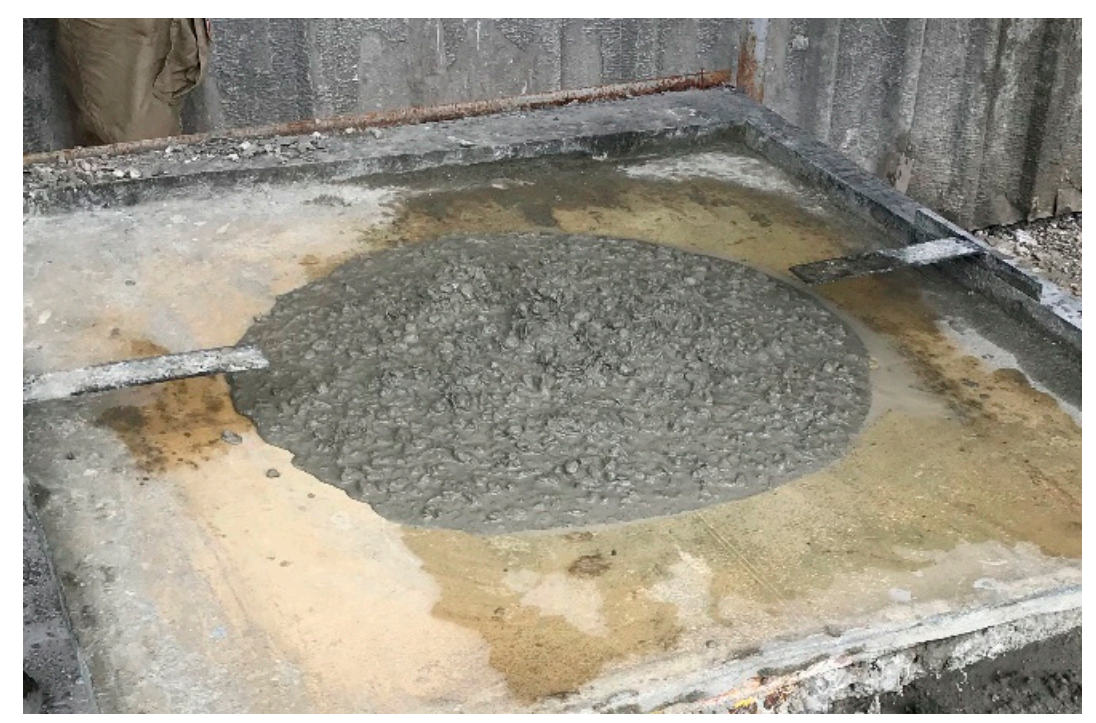

Figure 3. Flow test of FF6 giving evidence on the self-compacting properties of the material without segregation and bleeding. 


\subsection{Compressive Strength, Tensile Strength, and Modulus of Elasticity}

The test results for compressive strength, split tensile strength, and modulus of elasticity are summarized in Table 4 . The results are the average of three samples tested per batch for each test. The corresponding standard deviation is presented in brackets.

Table 4. Summary of the 28-day test results. Numbers in square brackets are standard deviation.

\begin{tabular}{cccc}
\hline Batch Designation & $\begin{array}{c}\text { Compressive Strength, } \\
f_{\boldsymbol{c m}} \mathbf{( M P a )}\end{array}$ & $\begin{array}{c}\text { Split Tensile } \\
\text { Strength, } f_{\text {ct.sp }}(\mathbf{M P a})\end{array}$ & $\begin{array}{c}\text { Modulus of Elasticity, } \\
\boldsymbol{E}_{\boldsymbol{c}}(\mathbf{M P a})\end{array}$ \\
\hline FF4 & $69.5[0.91]$ & $3.89[0.10]$ & $34,153[3535.6]$ \\
FF6 & $69.6[1.39]$ & $5.00[0.41]$ & $32,687[818.9]$ \\
FF8 & $52.7[0.90]$ & $2.28[0.58]$ & $28,968[3491.4]$ \\
\hline
\end{tabular}

Results revealed that batch FF4 and FF6, with $4 \mathrm{~kg} / \mathrm{m}^{3}$ and $6 \mathrm{~kg} / \mathrm{m}^{3}$ of fibers, respectively, had similar compressive strength and can be classified as high-strength concrete (50 MPa or higher). The major difference between the two mixtures was seen in the 28-day split tensile strength, where FF6 had $28 \%$ higher tensile strength compared to the FF4 mixture. The reason for the improvement of concrete tensile and compressive strength in the presence of fibers up to $6 \mathrm{~kg} / \mathrm{m}^{3}$ can be attributed to the ability of the fibers in preventing crack propagation, changing the crack orientation, and reducing the crack growth rate [24].

On the other hand, FF8 with a higher fiber dosage exhibited lower compressive strength, split tensile strength, and modulus of elasticity among all the concrete batches in this study. The mean compressive strength was $52.7 \mathrm{MPa}$, which still classifies the concrete as high strength concrete, but represents a $25 \%$ reduction in the compressive performance. The poorer results of FF8 are attributed to the poor fresh properties observed during casting. Although the mixture visually presented good fiber dispersion and enough paste, the fresh properties proved the material was not in the range of self-compacting concrete, and since no additional compaction was applied, it likely affected the compaction of the material in the cylinder mold, reducing the compressive and tensile strength. The modulus of elasticity appeared to decrease with the increase in fiber dosage, however, results are not conclusive due to the variations found in the test results.

\subsection{Flexural Strength and Residual Flexural Strength}

The average load $\mathrm{F}_{\mathrm{L}}$ and $\mathrm{F}_{1}$ to $\mathrm{F}_{4}$, average flexural strength $f_{L}$, and the average residual flexural strength $f_{R 1}$ to $f_{R 4}$ for the three concrete batches are summarized in Table 5 . These results were obtained from the recorded load vs. CMOD graphs using Equations (1) and (2). The corresponding load vs. CMOD graphs are presented in Figure 4

Table 5. Summary of 28-day flexural test results. Average flexural strength $f_{L}$ and residual flexural strength $f_{R j}$.

\begin{tabular}{ccccccccccc}
\hline Batch & $\boldsymbol{F}_{\mathbf{L}}$ & $\boldsymbol{F}_{\mathbf{1}}$ & $\begin{array}{c}\boldsymbol{F}_{\mathbf{2}} \\
\mathbf{( k N )}\end{array}$ & $\boldsymbol{F}_{\mathbf{3}}$ & $\boldsymbol{F}_{\mathbf{4}}$ & $f_{\mathbf{L}}$ & $f_{\boldsymbol{R} \mathbf{1}}$ & $\begin{array}{c}f_{\boldsymbol{R} \mathbf{2}} \\
\mathbf{( M P a})\end{array}$ & $f_{\boldsymbol{R} \mathbf{3}}$ & $f_{\boldsymbol{R} 4}$ \\
\hline FF4 & 16.13 & 5.58 & 5.65 & 5.38 & 4.60 & 5.16 & 1.78 & 1.81 & 1.72 & 1.47 \\
FF6 & 18.26 & 5.65 & 7.38 & 6.80 & 5.61 & 5.84 & 1.81 & 2.36 & 2.18 & 1.80 \\
FF8 & 15.32 & 9.45 & 11.28 & 10.66 & 9.00 & 4.90 & 3.02 & 3.61 & 3.41 & 2.88 \\
\hline
\end{tabular}




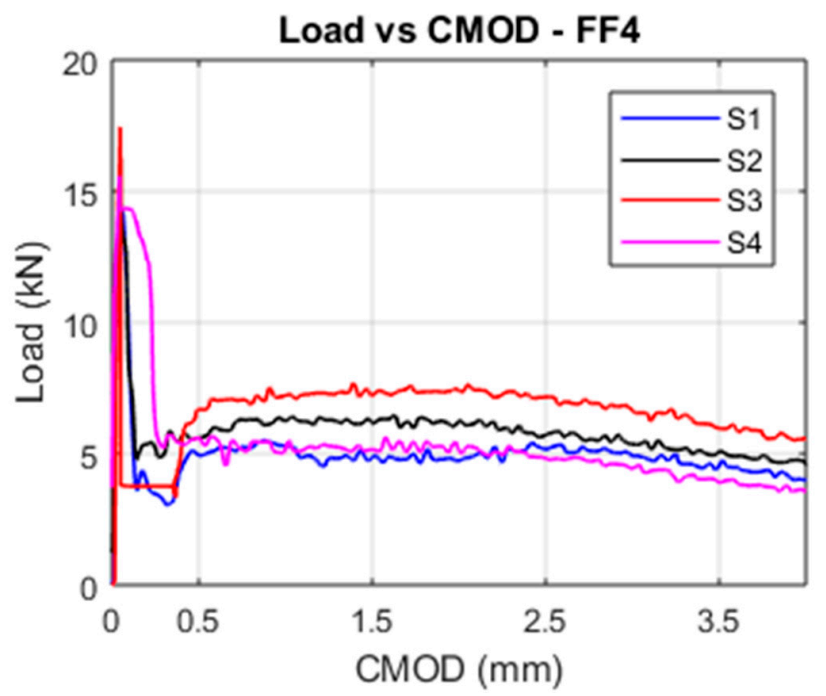

(a)

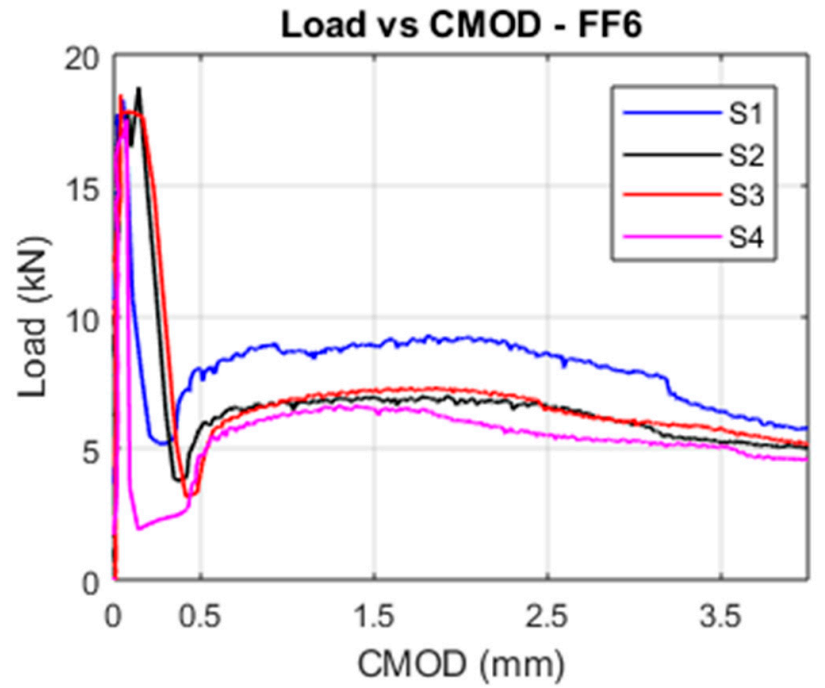

(b)

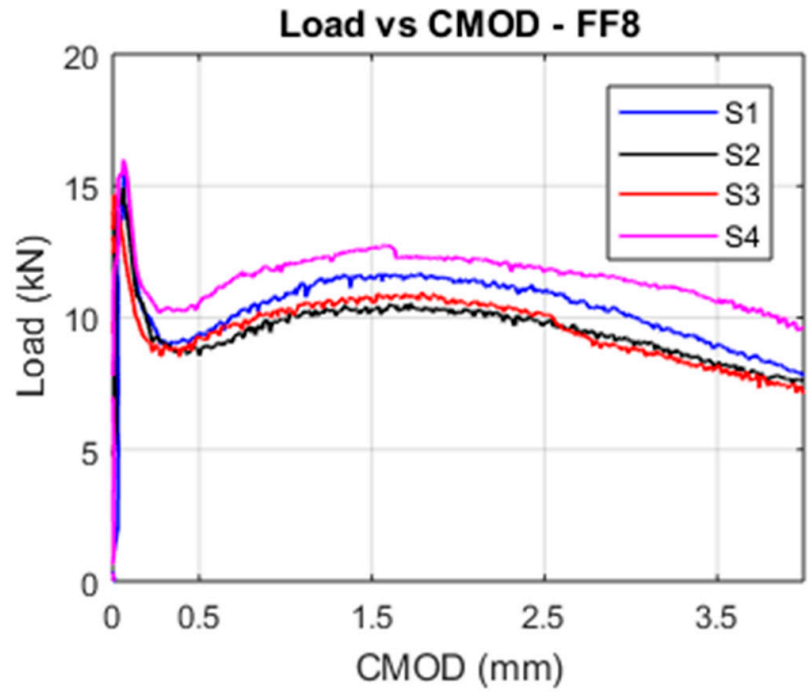

(c)

Figure 4. Load vs. crack-mouth opening displacement (CMOD) for (a) FF4, (b) FF6 and (c) FF8. 
To prevent brittleness in a structural member, the fib Model Code 2010 [34] suggest that fiber reinforcement can only be used if two conditions are satisfied: (i) $f_{R 1 k} / f_{L k} \geq 0.4$, and (ii) $f_{R 3 k} / f_{R 1 k} \geq 0.5$, with $f_{L k}, f_{R 1 k}$ and $f_{R 3 k}$ being the characteristic value of the nominal strength at peak load, the characteristic serviceability limit at CMOD1 and characteristic ultimate limit at CMOD3, respectively. The characteristic values are calculated using normal distribution, with confidence interval of 0.75 [34]. Table 6 presents the characteristic values $f_{L k}, f_{R 1 k}$, and $f_{R 3 k}$ of all batches and the ratios $f_{R 1 k} / f_{L k}$ and $f_{R 3 k} / f_{R 1 k}$. Table 7 presents the flexural strength ratio of all mixtures (rj) compared to FF4.

Table 6. Summary of the 28-day characteristic values of all batches according to the fib Model Code 2010.

\begin{tabular}{cccccc}
\hline Batch & $f_{L k}$ & $\begin{array}{c}f_{R 1 k} \\
\text { (MPa) }\end{array}$ & $f_{R 3 k}$ & $f_{R 1 k} / f_{L k}$ & $f_{R 3 k} / f_{R 1 k}$ \\
\hline FF4 & 4.88 & 1.42 & 1.44 & 0.29 & 1.01 \\
FF6 & 5.50 & 1.27 & 1.33 & 0.23 & 1.05 \\
FF8 & 4.51 & 2.49 & 2.83 & 0.55 & 1.14 \\
\hline
\end{tabular}

Table 7. Flexural strength ratio $\left(r_{j}\right)$ of all batches compared to FF4.

\begin{tabular}{cccccc}
\hline Batch & $\boldsymbol{r}_{\boldsymbol{L}}$ & $\boldsymbol{r}_{\mathbf{1}}$ & $\boldsymbol{r}_{\mathbf{2}}$ & $\boldsymbol{r}_{\mathbf{3}}$ & $\boldsymbol{r}_{\mathbf{4}}$ \\
\hline FF4 & 1.00 & 1.00 & 1.00 & 1.00 & 1.00 \\
FF6 & 1.13 & 1.01 & 1.31 & 1.26 & 1.22 \\
FF8 & 0.95 & 1.69 & 2.00 & 1.98 & 1.96 \\
\hline
\end{tabular}

It is reported in the literature that the flexural strength of SCC reinforced with monofilament polypropylene fibers is affected by the fiber content, and when compared with plain concrete the flexural strength of fiber reinforced concrete is significantly higher [17]. Another recent study on the fracture parameters and size effect of steel fiber-reinforced self-compacting concrete [36] found that an increase in the steel fiber dosage increases energy absorption and ductility. For high-strength SCC reinforced with twisted-bundle macro-synthetic fiber, the increase in fiber dosage from $4 \mathrm{~kg} / \mathrm{m}^{3}$ to $6 \mathrm{~kg} / \mathrm{m}^{3}$ increased the overall flexural performance (Table 7), however, the further increase to $8 \mathrm{~kg} / \mathrm{m}^{3}$ resulted in a reduction of $5 \%$ in the flexural strength. The same trend was observed in the compression strength and can be attributed to the poor self-compacting properties of FF8. However, the most prominent contribution of the additional $4 \mathrm{~kg} / \mathrm{m}^{3}$ was observed in the post-cracking behavior. Comparing the serviceability limit expressed by $f_{R 1 k} / f_{L k}$, presented in Table 6, FF8 was the only composite that satisfy the requirement to prevent brittle failure in structural member proposed by the $f i b$ Model Code $2010\left(f_{R 1 k} / f_{L k} \geq 0.4\right.$, and $\left.f_{R 3 k} / f_{R 1 k} \geq 0.5\right)$. The residual flexural strength $f_{R 1}$ of FF8 increased by $69 \%$ when compared to FF4, while $f_{R 2}, f_{R 3}$, and $f_{R 4}$ doubled, evidencing the fiber contribution post-cracking.

In contrast to FF8, batches FF4 and FF6 did not satisfy the first requirement to prevent brittleness failure $\left(f_{R 1 k} / f_{L k} \geq 0.4\right)$. However, the results obtained for the $f_{R 3 k} / f_{R 1 k}$ indicate the effectiveness of the fibers bridging up to the ultimate limit state at CMOD3. Table 7 shows that the gradual increase in fiber content increases the composite post-cracking performance from CMOD1 to CMOD4. This is corroborated by the $f_{R 3 k} / f_{R 1 k}$ ratio, presented in Table 6 , clearly indicating the effect of the fiber dosage, i.e., it increases the ultimate performance of the composite.

As discussed by Li [35], in plain concrete crack bridging is provided by aggregate locking action. When fibers are added to concrete, additional bridging action is brought into effect, superimposing on the aggregate bridging effect. It should be recognized that at the formation of a matrix crack, and prior to any crack opening, the fiber is already in a stressed state. Thus, the combined crack bridging mechanisms depends on the individual contributions of the aggregate bridging action, the fiber bridging action, and the fiber prestress. Indeed, the fiber content plays a significant role in the bridging action observed in the post-cracking stage. As observed in results presented in Tables $5-7$, 
the fiber content has not directly increased the SCC flexural strength but has significantly affected the post-cracking performance of the composites.

Jenq and Shah [36] further describe the mechanism of fracture resistance for fiber-reinforced concrete in three stages: (i) The subcritical crack growth in the matrix and the beginning of the fiber bridging effect; (ii) the post-critical crack growth in the matrix, where the fiber-bridging closing stresses remains constant, and (iii) the final stage, where the resistance to crack separation is provided exclusively by fibers. Figure 5 . Fibers bridging the crack shows the fibers bridging the crack at the final fracture stage in the FF8 beam at CMOD4 $=3.5 \mathrm{~mm}$.

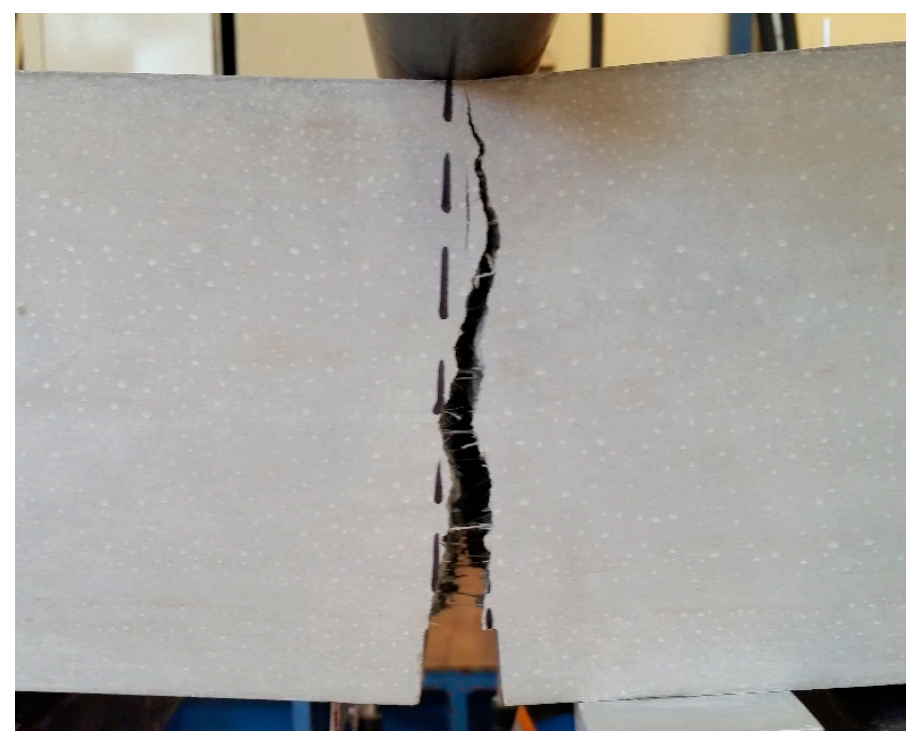

(a)

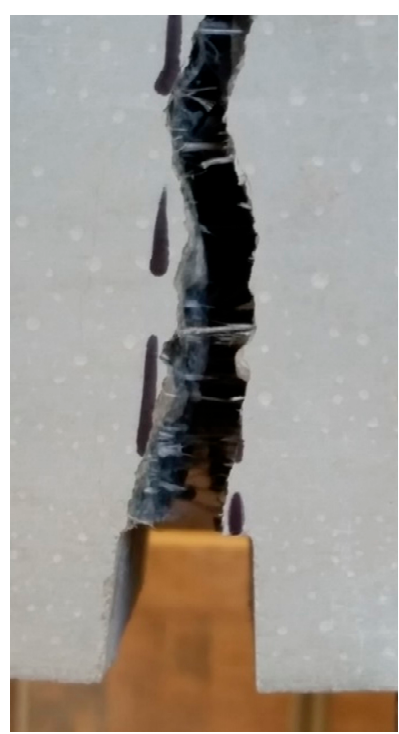

(b)

Figure 5. (a) Fibers bridging the crack; (b) Zoom on the wider section of the crack.

\section{Theoretical Approach and Discussion}

\subsection{Material Behavior}

The fib Model Code 2010 [34] presents the most comprehensive design guidelines for fiber-reinforced concrete, focusing both on material behavior and structural behavior. The basic principles introduced are mainly obtained from research of steel fiber reinforced concrete (SFRC), but the fib model is adaptable to other types of fibers [37]. SFRC exhibits strain-softening behavior, as shown in Figure 6. Simplified load-deformation curves; (a) strain softening, and (b) strain hardening [37]. However, this strain softening-behavior can be different for FRC incorporating synthetic fibers.
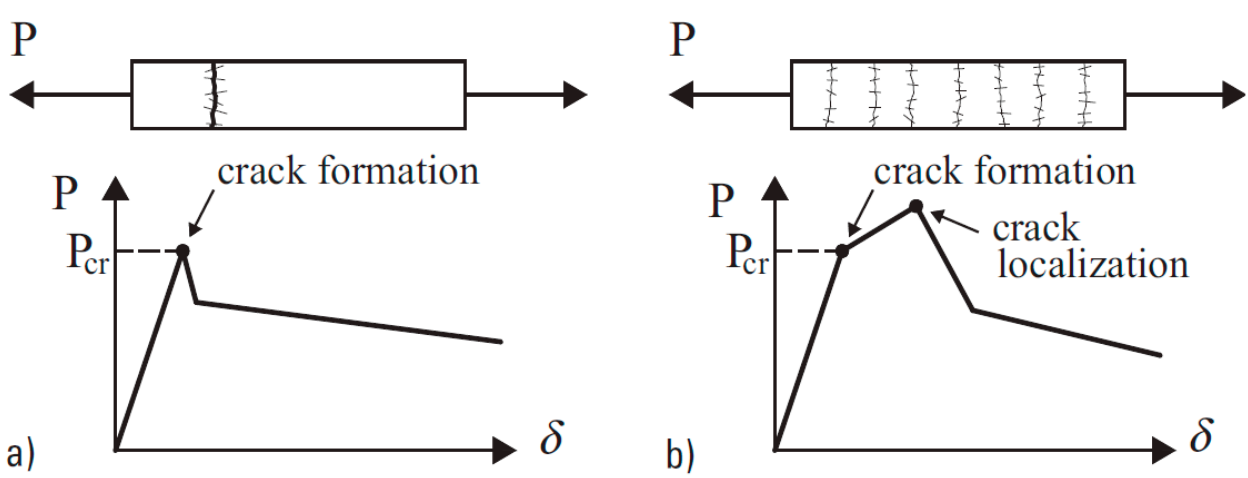

Figure 6. Simplified load-deformation curves; (a) strain softening, and (b) strain hardening [37]. 
A typical load vs. CMOD curve for plain concrete and SFRC is depicted in Figure 7a. While comparing against Figure 4 it is evident that even though both SFRC and twisted-bundle macro-synthetic fiber FRC demonstrate strain-softening behavior, the decrease in load value after CMOD1 $=0.5 \mathrm{~mm}$ is slightly different. For instance, for SRFC F1 > F2 > F3 > F4, as seen in Figure 7a, with the typical stress distribution shown in Figure $7 \mathrm{~b}$. However, for the twisted-bundle macro-synthetic fiber-reinforced SCC, the load remains almost constant up to CMOD3 $=2.5 \mathrm{~mm}$, followed by a softening behavior.

(a)

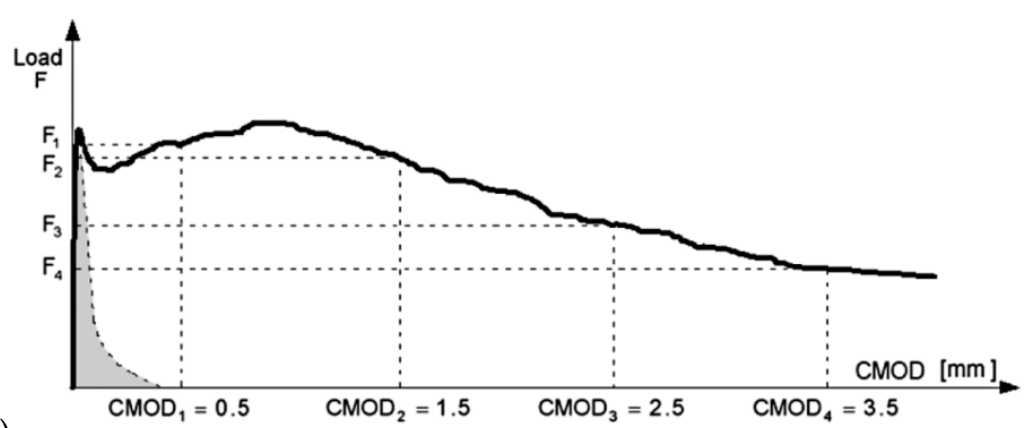

Figure 7. (a) Typical load vs. CMOD curve for plain concrete (in grey) and fiber-reinforced concrete (FRC) (in black) and (b) Stress distributions assumed for FRC in the fib Model [37].

In order to predict the moment capacity of a FRC element under bending, the material behavior, particularly the stress-strain behavior of FRC, should be defined first. The loads in Figure 4 can be converted to flexural and residual flexural strengths, using Equations (1) and (2). Figure 8 displays the stress vs. CMOD curves (dashed lines) along with simplified curves connecting maximum stress, stress corresponding to CMOD1, CMOD2, CMOD3, and CMOD4 (solid lines). It can be noted here that the CMOD1 corresponds to the serviceability limit state, whereas the CMOD3 usually corresponds to the ultimate limit state [37]. Since the stress remained almost constant between CMOD1 to CMOD3, it can be assumed that $f_{R 1}=f_{R 3}$, and a simplified model can be proposed, as shown in Figure 9. In addition, it can be seen that the drop in magnitude from $f_{L}$ to $f_{R 1}$ is less as the fiber dosage increases from $4 \mathrm{~kg} / \mathrm{m}^{3}$ to $8 \mathrm{~kg} / \mathrm{m}^{3}$. The $f_{R 1} / f_{L}$ ratio of the four samples of the three different mixtures are tabulated in Table 8. $f_{R 1} / f_{L}$ ratio of all tested samples for three different mixtures, the average and standard deviation of each mixture are also presented. The ratio is within an acceptable standard deviation for FF4 and FF8, while FF6 exhibited a significant variation. Even though the variation for FF6 is high, it can be assumed as a general trend that the $f_{R 1} / f_{L}$ ratio increases with the increase in fiber dosage. 


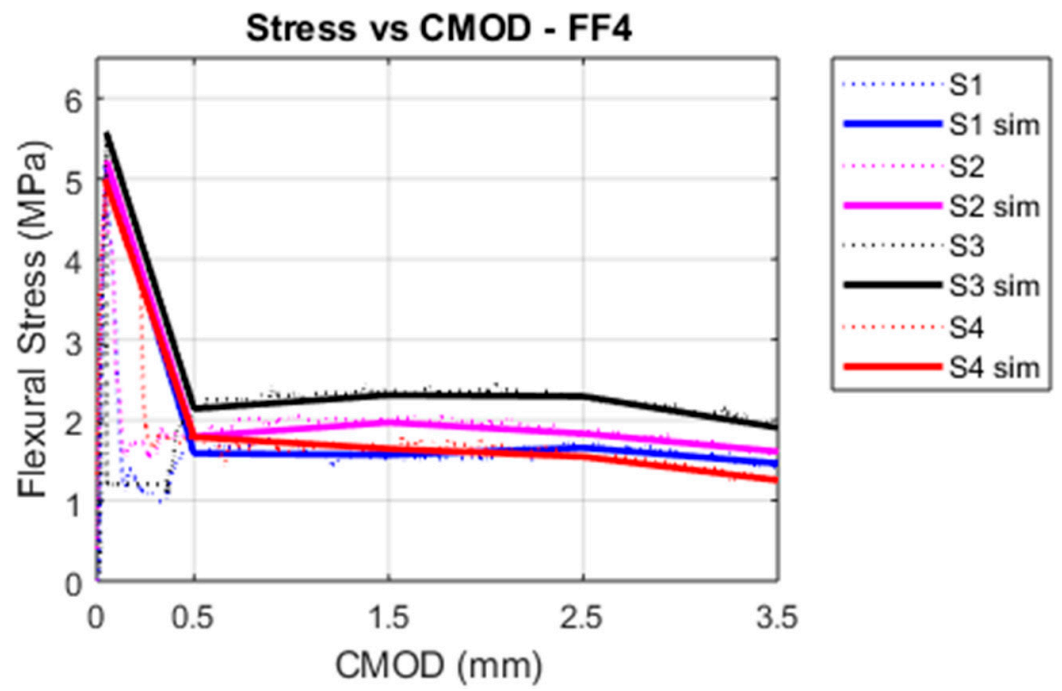

(a)

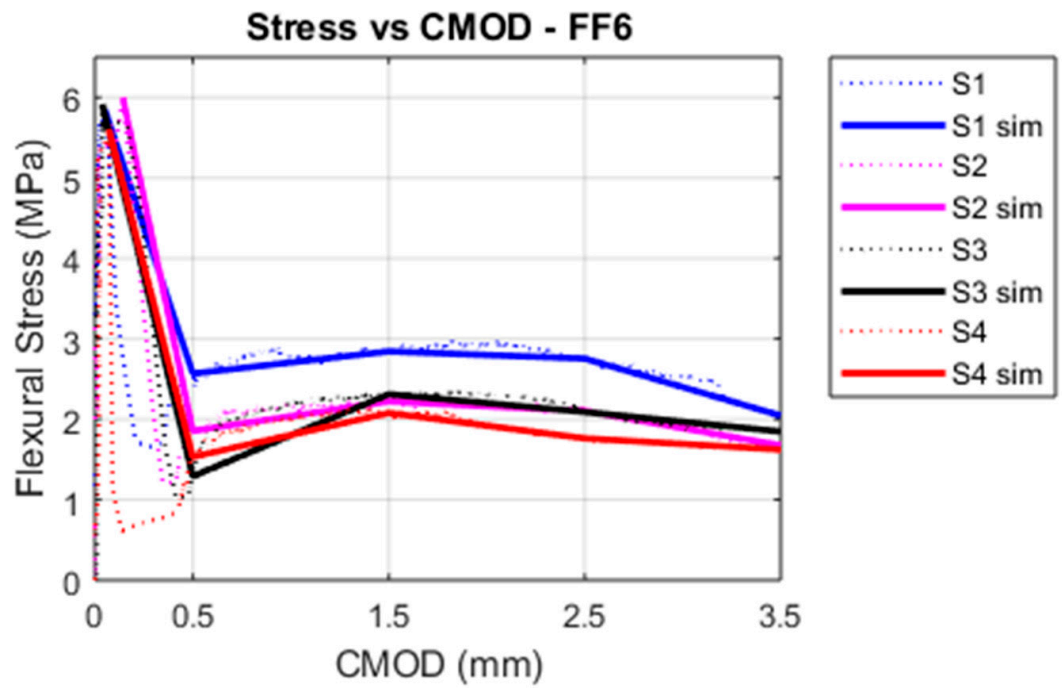

(b)

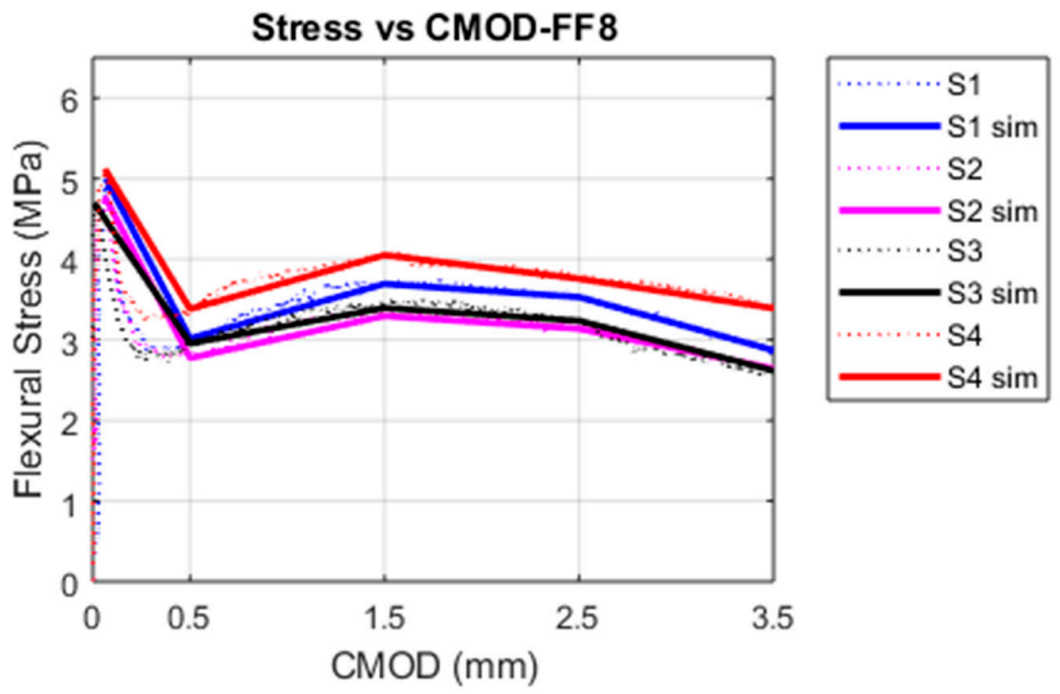

(c)

Figure 8. Flexural stress vs. CMOD plots for (a) FF4, (b) FF6 and (c) FF8, along with the corresponding line connecting maximum stress to stress at CMOD1, CMOD2, CMOD3, and CMOD4. 


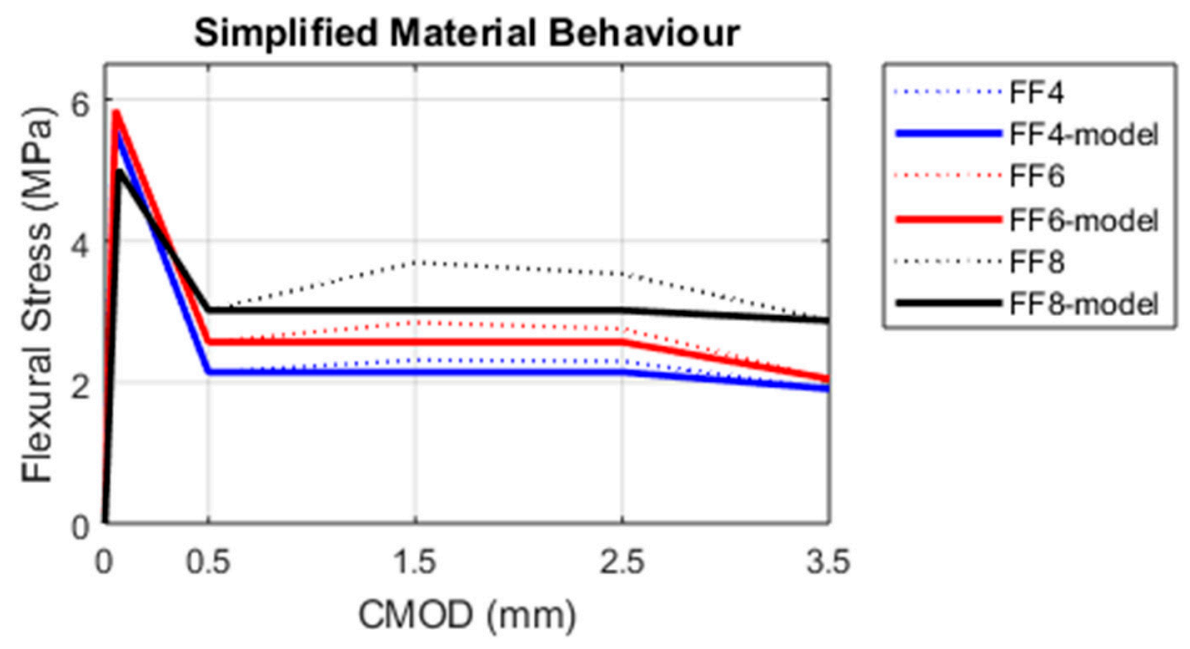

Figure 9. Simplified stress vs. CMOD model behavior for twisted-bundle macro-synthetic fiber reinforced self-compacting concrete (SCC). A trilinear constitutive model was adopted.

Table 8. $f_{R 1} / f_{L}$ ratio of all tested samples for three different mixtures.

\begin{tabular}{|c|c|c|c|c|c|c|c|c|c|c|c|c|}
\hline \multirow{2}{*}{$\begin{array}{l}\text { Mixture } \\
\text { Samples }\end{array}$} & \multicolumn{4}{|c|}{ FF4 } & \multicolumn{4}{|c|}{ FF6 } & \multicolumn{4}{|c|}{ FF8 } \\
\hline & S1 & S2 & S3 & S4 & S1 & S2 & S3 & S4 & S1 & S2 & S3 & S4 \\
\hline$f_{R 1} / f_{L}$ & 0.31 & 0.34 & 0.38 & 0.36 & 0.43 & 0.31 & 0.21 & 0.27 & 0.6 & 0.58 & 0.63 & 0.66 \\
\hline Av [Std] & \multicolumn{4}{|c|}{$0.35[0.03]$} & \multicolumn{4}{|c|}{$0.31[0.09]$} & \multicolumn{4}{|c|}{$0.62[0.03]$} \\
\hline$A v+S t d$ & \multicolumn{4}{|c|}{0.38} & \multicolumn{4}{|c|}{0.40} & \multicolumn{4}{|c|}{0.65} \\
\hline
\end{tabular}

\subsection{Constitutive Law and Bending Moment Prediction}

The fib Model Code [34] proposes the following relationship for the ultimate residual flexural strength $f_{\text {ult }}$ based on SFRC for a rigid plastic model (Equation (3)):

$$
f_{u l t}=f_{R 3} / 3
$$

While this equation is suitable for FRC with softening behavior, it requires the notch beam test results and is developed based on the performance of SFRC. It would be of great interest to predict the ultimate strength or moment capacity of a FRC beam by knowing the split tensile strength of FRC obtained from a simple indirect tensile strength testing only. Therefore, this study proposes a technique to relate the ultimate flexural strength of synthetic fiber reinforced SCC using the split tensile strength.

To relate the ultimate residual flexural strength $\left(f_{\text {ult }}\right)$ of the SCC with split tensile strength $f_{\text {ct.sp }}$, it can be logically assumed that the fiber content contributes to the residual flexural strength. This is due to the fact that even though the split tensile strength of plain concrete and FRC is very similar, the flexural failure of plain concrete occurs at a CMOD of less than $0.5 \mathrm{~mm}$, as depicted in Figure 7a. In contrast, significant residual stress is obtained for FRC from CMOD 0.5 to $2.5 \mathrm{~mm}$ (Figure 9). Since the ultimate residual flexural strength $\left(f_{u l t}\right)$ is associated with $2.5 \mathrm{~mm}$ (CMOD3), it can be related to the split tensile strength using Equation (4).

$$
f_{u l t}=k_{f} f_{c t . s p}
$$

where, $f_{\text {ct.sp }}=$ split tensile strength of FRC, $f_{\text {ult }}=$ ultimate residual flexural strength corresponding to ultimate crack mouth opening $(2.5 \mathrm{~mm})$, and $k_{f}=$ factor related to fiber dosage.

As discussed above, the fiber contributes to the gaining of residual flexural strength. As a result, $f_{u l t}$ should be related to fiber dosage, which is taken into account by the factor $k_{f}$. This factor is calibrated by Equation (5).

$$
k_{f}=f_{R 1} / f_{L}
$$


The determination of the ratio $f_{R 1} / f_{L}$ is discussed in Table 8 . It can be noted here that the authors are currently working on developing a fiber dosage vs. $k_{f}$ curve that will eliminate the use of the notch beam testing; thus the ultimate residual flexural strength can be determined by simply using Equation (4).

At failure, as seen in Figure 5, the crack reached the top surface of the concrete beam where the crack width is considered to reach the serviceability limit $(0.5 \mathrm{~mm})$, while the crack width at the bottom is considered to reach the ultimate limit $(2.5 \mathrm{~mm})$. Figure 9 shows that the stress is constant between the CMOD of 0.5 to $2.5 \mathrm{~mm}$. As plastic deformation is observed between 0.5-2.5 mm CMOD (Figures 9 and 10a), the whole critical cross-section of the beam is subjected to the tensile post-cracking residual stress (Figure 10b). Again, as the crack reached the top surface of the beam, it can be assumed that the compressive stress is concentrated at the top fiber. Hence, the ultimate moment capacity can be determined using Equation (6).

$$
M_{\text {u.theo }}=T_{f} \frac{h_{s p}}{2}=\left(f_{u l t} b h_{s p}\right) \frac{h_{s p}}{2}=\frac{f_{u l t} b h_{s p}^{2}}{2}
$$

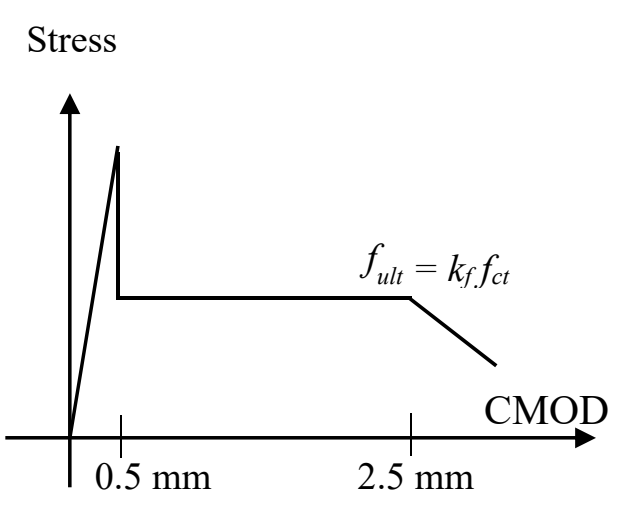

(a)

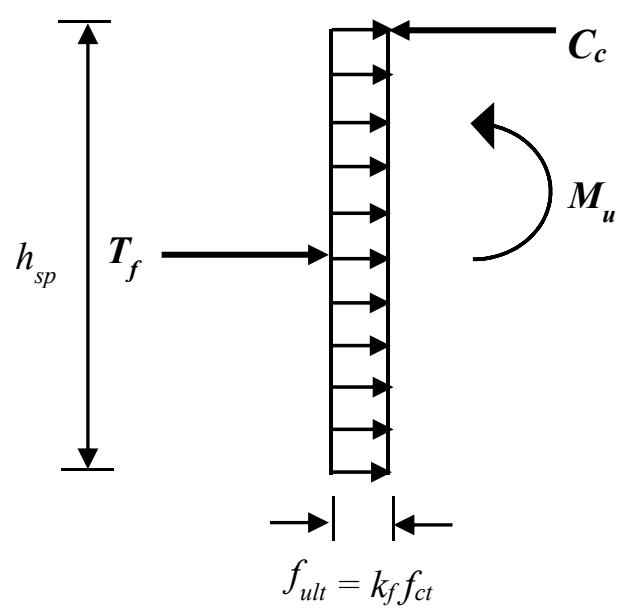

(b)

Figure 10. (a) Modified stress-crack opening constitutive law, (b) Stress and forced distribution at ultimate moment based on modified model.

\subsection{Comparison of the Theoretical and Experimental Moment Capacity}

The calculated theoretical moment capacity for each batch, calculated from Equation 6, is compared in Table 9 with the experimental moment capacities for each of the corresponding batch specimens from the experimental results discussed above. In addition, a comparison is made between Equation 3 and 4 to calculate $f_{\text {ult }}$. The $k_{f}$ value for FF4, FF6, and FF8 is determined as the average plus the standard deviation of the ratios $f_{R 1} / f_{L}$ from Table 8 , resulting in $k_{f}=0.38,0.40$, and 0.65 for FF4, FF6, and FF8, respectively. $M_{u, \text { theo. } 1}$ is determined using Equation 3 and $M_{u, \text { theo. } 2}$ is determined using Equation 4. The ratio of the experimental to theoretical moment $M_{u, \exp } / M_{u, \text { theo }}$ capacities shows that, although conservative, the modified stress distribution model is a fairer predictor for the moment capacity when compared to the model proposed in the fib Model Code [34]. The moment capacity prediction for FF8, and to a lesser extent FF4, is slightly conservative but is not conservative for FF6. Nevertheless, FF6 yields a very precise result compared to FF4 and FF8. While comparing the proposed model and the fib Model Code [34], it is evident that the proposed model is more accurate in terms of predicting the moment capacity of twisted-bundle macro-synthetic fiber reinforced SCC. 
Table 9. Experimental and theoretical moment capacity of twisted-bundle macro-synthetic fiber reinforced SCC samples.

\begin{tabular}{|c|c|c|c|c|c|c|c|}
\hline Mixture & Samples & $\begin{array}{c}P_{u, \exp } \\
(\mathrm{kN})\end{array}$ & $\begin{array}{c}M_{u, \exp } \\
\text { (kN.m) }\end{array}$ & $\begin{array}{c}M_{u, \text { theo. } 1} \\
\text { (kN.m) }\end{array}$ & $\frac{M_{u, e x p}}{M_{u, t h e o .1}}$ & $\begin{array}{c}M_{u, t h e o .2} \\
\text { (kN.m) }\end{array}$ & $\frac{M_{u, \text { exp }}}{M_{u, \text { theo. } 2}}$ \\
\hline \multirow{4}{*}{ FF4 } & S1 & 16.12 & 2.02 & 0.65 & 3.12 & \multirow{4}{*}{1.73} & 1.16 \\
\hline & S2 & 16.32 & 2.04 & 0.72 & 2.85 & & 1.17 \\
\hline & S3 & 17.44 & 2.18 & 0.9 & 2.43 & & 1.25 \\
\hline & S4 & 15.59 & 1.95 & 0.6 & 3.23 & & 1.12 \\
\hline \multirow{4}{*}{ FF6 } & S1 & 18.28 & 2.29 & 1.08 & 2.12 & \multirow{4}{*}{2.34} & 0.97 \\
\hline & S2 & 18.75 & 2.34 & 0.82 & 2.85 & & 0.99 \\
\hline & S3 & 18.48 & 2.31 & 0.82 & 2.83 & & 0.99 \\
\hline & $\mathrm{S} 4$ & 17.52 & 2.19 & 0.69 & 3.18 & & 0.93 \\
\hline \multirow{4}{*}{ FF8 } & S1 & 15.64 & 1.96 & 1.38 & 1.42 & \multirow{4}{*}{1.74} & 1.12 \\
\hline & $\mathrm{S} 2$ & 14.94 & 1.87 & 1.23 & 1.52 & & 1.07 \\
\hline & S3 & 14.68 & 1.84 & 1.26 & 1.45 & & 1.06 \\
\hline & $\mathrm{S} 4$ & 16.00 & 2.00 & 1.47 & 1.36 & & 1.15 \\
\hline
\end{tabular}

Assuming three mixtures with 4,6 , and $8 \mathrm{~kg} / \mathrm{m}^{3}$ of fibers and similar split tensile properties, a theoretical comparison can be made among them to compare their theoretical moment capacity. Providing that the split tensile strength of all the concrete mixture is $4 \mathrm{MPa}$, the theoretical section moments are 1.78, 1.88, and $3.05 \mathrm{kN}$.m, respectively. Hence, it can be concluded that the FF8 mixture has the highest moment-carrying capacity.

\section{Conclusions}

This paper investigated the fresh and mechanical properties of high-strength self-compacting concrete reinforced with twisted-bundle macro-synthetic fibers, and proposed a theoretical model to predict the ultimate flexural strength of synthetic fiber reinforced SCC. The main findings of this work are as follow:

- The inclusion of fibers up to $6 \mathrm{~kg} / \mathrm{m}^{3}$ did not affect the flowabilty of the self-compacting concrete. The mixture containing $8 \mathrm{~kg} / \mathrm{m}^{3}$ presented reduced flowability and would require further mixture design improvements in order to achieve the desirable self-compacting properties for precast applications;

- The mixture with a dosage of $6 \mathrm{~kg} / \mathrm{m}^{3}$ exhibited the highest compressive and tensile strength. However, when flexural and post-cracking performances were assessed, the mixture with $8 \mathrm{~kg} / \mathrm{m}^{3}$ revealed improved flexural performance compared to lower fiber dosages, evidencing the contribution of higher fiber contents in the post-cracking composite performance;

- Based on the post-cracking behavior, a modified stress-crack opening constitutive law was proposed, including fiber dosage as a model parameter. This model predicts the moment capacity of FRC beams by using the split tensile strength of FRC and a coefficient correlated to fiber content/dosage. The model also corroborates the conclusion that the highest fiber content of $8 \mathrm{~kg} / \mathrm{m}^{3}$ results in a higher moment carrying capacity.

- The model is an initial approach on the development of a theoretical model to predict the ultimate flexural strength of synthetic fiber-reinforced SCC based on split tensile strength only, without relying on notch beam flexural test and is capable of predicting the flexural strength of FRC beam.

Author Contributions: Conceptualization, E.O.G. and A.M.; methodology, E.O.G.; formal analysis, M.I.K., K.G., and M.S.; validation, K.G. and M.S.; investigation, E.O.G. and A.M.; writing-original draft preparation, M.I.K. and M.S.; writing-review and editing, E.O.G.; funding acquisition, E.O.G.

Funding: This research received external funding from the Innovation Connection Scheme, Australian Government, and Holmes Nominees (AUST) PTY. LTD. 
Acknowledgments: The authors would like to thank Lube Veljanoski for his support during the experimental tests; Local Mixture, Geelong for preparing the mixtures; and Geelong Concrete for preparing the samples.

Conflicts of Interest: The authors declare no conflict of interest.

\section{References}

1. Sivakumar, A.; Santhanam, M. Mechanical properties of high strength concrete reinforced with metallic and non-metallic fibres. Cem. Concr. Compos. 2007, 29, 603-608. [CrossRef]

2. Pons, G.; Mouret, M.; Alcantara, M.; Granju, J.L. Mechanical behaviour of self-compacting concrete with hybrid fibre reinforcement. Mater. Struct. 2007, 40, 201-210. [CrossRef]

3. Buratti, N.; Mazzotti, C.; Savoia, M. Post-cracking behaviour of steel and macro-synthetic fibre-reinforced concretes. Constr. Build. Mater. 2011, 25, 2713-2722. [CrossRef]

4. Balendran, R.V.; Zhou, F.P.; Nadeem, A.; Leung, A.Y.T. Influence of steel fibres on strength and ductility of normal and lightweight high strength concrete. Build. Environ. 2002, 37, 1361-1367. [CrossRef]

5. Banthia, N.; Nandakumar, N. Crack growth resistance of hybrid fiber reinforced cement composites. Cem. Concr. Compos. 2003, 25, 3-9. [CrossRef]

6. Staff, B.S.I.; Institution, B.S. Test Method for Metallic Fibre Concrete. Measuring the Flexural Tensile Strength (Limit of Proportionality (LOP), Residual); BSI Standards: London, UK, 2005; BS EN 14651:2005+A1:2007.

7. Society, C. Guidance for the Design Of Steel-fibre-reinforced Concrete; Technical Report 63; Concrete Society: Camberley, UK, 2007.

8. Japan Society of Civil Engineers. Method of Tests for Flexural Strength and Flexural Toughness of Steel Fiber Reinforced Concrete; Japan Society of Civil Engineers: Tokyo, Japan, 1984.

9. ASTM International. Standard Specification for Steel Fibers for Fiber-Reinforced Concrete; ASTM International: West Conshohocken, PA, USA, 2016; ASTM A820/A820M.

10. Okamura, H.; Ouchi, M. Self-compacting concrete. J. Adv. Concr. Technol. 2003, 1, 5-15. [CrossRef]

11. Goodier, C.I. Development of self-compacting concrete. Loughb. Univ. Inst. Repos. 2003, 156, 405-414. [CrossRef]

12. Domone, P.L. Self-compacting concrete: An analysis of 11 years of case studies. Cem. Concr. Compos. 2006, 28, 197-208. [CrossRef]

13. Foraboschi, P. Versatility of steel in correcting construction deficiencies and in seismic retrofitting of RC buildings. J. Build. Eng. 2016, 8, 107-122. [CrossRef]

14. Song, P.S.; Hwang, S. Mechanical properties of high-strength steel fiber-reinforced concrete. Constr. Build. Mater. 2004, 18, 669-673. [CrossRef]

15. Corinaldesi, V.; Moriconi, G. Durable fiber reinforced self-compacting concrete. Cem. Concr. Res. 2004, 34, 249-254. [CrossRef]

16. Ding, Y.; Liu, S.; Zhang, Y.; Thomas, A. The investigation on the workability of fibre cocktail reinforced self-compacting high performance concrete. Constr. Build. Mater. 2008, 22, 1462-1470. [CrossRef]

17. Gencel, O.; Brostow, W.; Datashvili, T.; Thedford, M. Workability and mechanical performance of steel fiber-reinforced self-compacting concrete with fly ash. Compos. Interfaces 2011, 18, 169-184. [CrossRef]

18. Pajakk, M.; Ponikiewski, T. Flexural behavior of self-compacting concrete reinforced with different types of steel fibers. Constr. Build. Mater. 2013, 47, 397-408. [CrossRef]

19. Sahmaran, M.; Yaman, I.O. Hybrid fiber reinforced self-compacting concrete with a high-volume coarse fly ash. Constr. Build. Mater. 2007, 21, 150-156. [CrossRef]

20. Sahmaran, M.; Yurtseven, A.; Yaman, I.O. Workability of hybrid fiber reinforced self-compacting concrete. Build. Environ. 2005, 40, 1672-1677. [CrossRef]

21. Barros, J.; Pereira, E.; Santos, S. Lightweight panels of steel fiber-reinforced self-compacting concrete. J. Mater. Civ. Eng. 2007, 19, 295-304. [CrossRef]

22. Gencel, O.; Ozel, C.; Brostow, W.; Martínez-Barrera, G. Mechanical properties of self-compacting concrete reinforced with polypropylene fibres. Mater. Res. Innov. 2011, 15, 216-225. [CrossRef]

23. Alberti, M.G.; Enfedaque, A.; Gálvez, J.C. On the mechanical properties and fracture behavior of polyolefin fiber-reinforced self-compacting concrete. Constr. Build. Mater. 2014, 55, 274-288. [CrossRef] 
24. Hasan-Nattaj, F.; Nematzadeh, M. The effect of forta-ferro and steel fibers on mechanical properties of high-strength concrete with and without silica fume and nano-silica. Constr. Build. Mater. 2017, 137, 557-572. [CrossRef]

25. Arafa, M.H.; Alqedra, M.A.; Almassri, H.G. Effect of forta-ferro fibers on fresh and mechanical properties of ultra high performance self compacting concrete. Int. J. Eng. Tech. Res. 2013, 1, 43-47.

26. Balaguru, R.N.P.; Mehendra, P. Flexural Toughness of Steel Fiber Reinforced Concrete. Mater. J. 1992, $89,541-546$.

27. Hillerborg, A. Analysis of fracture by means of the fictitious crack model, particularly for fibre reinforced concrete. Int. J. Cem. Compos. 1980, 2, 177-184.

28. Hillerborg, A.; Modéer, M.; Petersson, P.E. Analysis of crack formation and crack growth in concrete by means of fracture mechanics and finite elements. Cem. Concr. Res. 1976, 6, 773-781. [CrossRef]

29. Methods of Testing Concrete Determination of Properties Related to the Consistency of Concrete—Slump Flow, T500 and J-Ring Test; Australian Standards: Sydney, Australia, 2015; A. 1012.3.5.

30. Yin, S.; Tuladhar, R.; Riella, J.; Chung, D.; Collister, T.; Combe, M.; Sivakugan, N. Comparative evaluation of virgin and recycled polypropylene fibre reinforced concrete. Constr. Build. Mater. 2016, 114, 134-141. [CrossRef]

31. Yin, S.; Tuladhar, R.; Shi, F.; Combe, M.; Collister, T.; Sivakugan, N. Use of macro plastic fibres in concrete: A review. Constr. Build. Mater. 2015, 93, 180-188. [CrossRef]

32. Richardson, A.; Coventry, K. Dovetailed and hybrid synthetic fibre concrete-Impact, toughness and strength performance. Constr. Build. Mater. 2015, 78, 439-449. [CrossRef]

33. Paulo, F.; Veludo, J.; Rodrigues, H.; Almeida, N.; Baptista, J. Self-compacting fiber reinforced concrete for precast industry. Int. J. Struct. Civ. Eng. Res. 2017, 7, 189-193.

34. New Model Code Fib Special Activity Group; Taerwe, L.; Matthys, S. Fib Model Code for Concrete Structures 2010; Ernst \& Sohn, Wiley: Berlin, Germany, 2013.

35. Li, V.C.; Stang, H.; Krenchel, H. Micromechanics of crack bridging in fibre-reinforced concrete. Mater. Struct. 1993, 26, 486-494. [CrossRef]

36. Jenq, Y.S.; Shah, S.P. Crack propagation in fiber reinforced concrete. J. Struct. Eng. 1986, 112, 19-34. [CrossRef]

37. Di Prisco, M.; Colombo, M.; Dozio, D. Fibre-reinforced concrete in fib Model Code 2010: Principles, models and test validation. Struct. Concr. 2013, 14, 342-361. [CrossRef] 